OPEN ACCESS

Edited by:

Ying-Yong Zhao,

Northwest University, China

Reviewed by:

Yani He,

Daping Hospital, China

Dongshan Zhang,

Central South University, China

Hangxing Yu,

First Teaching Hospital of Tianjin University of Traditional Chinese

Medicine, China

*Correspondence:

GuangYan Cai

caiguangyan@sina.com

JiJun Li

lijj9536@sina.com

tThese authors have contributed equally to this work

Specialty section:

This article was submitted to Nephrology,

a section of the journa

Frontiers in Medicine

Received: 12 May 2021

Accepted: 05 July 2021

Published: 09 August 2021

Citation:

Duan Z, Cai G, Li J, Chen F and Chen X (2021) Meta-Analysis of Renal

Replacement Therapy for Burn

Patients: Incidence Rate, Mortality, and Renal Outcome.

Front. Med. 8:708533.

doi: 10.3389/fmed.2021.708533

\section{Meta-Analysis of Renal Replacement Therapy for Burn Patients: Incidence Rate, Mortality, and Renal Outcome}

\author{
ZhiYu Duan ${ }^{1,2}$, GuangYan Cai ${ }^{1 \star \dagger}$, JiJun $\mathrm{Li}^{1,2 \star \dagger}$, FengKun Chen ${ }^{1,2}$ and XiangMei Chen ${ }^{1}$ \\ ' State Key Laboratory of Kidney Diseases, Department of Nephrology, National Clinical Research Center for Kidney Diseases, \\ Chinese People's Liberation Army Institute of Nephrology, Chinese People's Liberation Army General Hospital, Beijing, China, \\ ${ }^{2}$ Department of Nephrology, The Fourth Medical Center of People's Liberation Army General Hospital, Beijing, China
}

Background: Renal replacement therapy (RRT) was often needed by some severe burn patients with acute kidney injury (AKI). The primary aim of this study was to review incidence rate and mortality of RRT in severe burn patients. Second aims were to review RRT complications and renal outcome.

Methods: We searched multiple databases for studies published between 1 January 1960 and 31 December 2019. Studies about adult populations with burn injury, providing epidemiologic data on prevalence or mortality of RRT, were included.

Results: A total of selected 57 studies, including 27,437 patients were enrolled in our analysis. The prevalence rates of RRT were 8.34\% (95\% Cl 7.18-9.5\%) in all burn patients and $37.05 \%(95 \% \mathrm{Cl} 29.85-44.24 \%)$ in AKI patients. The mortality of all burn patients with RRT was $65.52 \%$ (95\% Cl 58.41-72.64\%). The prevalence rates of RRT in sample size $\geq 100$ group were $6.86 \%$ (95\% Cl 5.70-8.03\%), which was lower than that of $<100$ group $(17.61 \%, 95 \% \mathrm{Cl} 13.39-21.82 \%)$. With the increase of TBSA, the prevalence of RRT may have the increasing trend. The prevalence rates of RRT in Asian group was $12.75 \%$ (95\% Cl 9.50-16.00\%), which was higher than that of European (10.45\%, 95\% Cl 7.30-13.61\%) and North America group (5.61\%, 95\% Cl 4.27-6.95\%). The prevalence rates of RRT in 2010-2019 group was 12.22\% (95\% Cl 10.09-14.35\%), which was higher than that of 2009-2000 group (5.17\%, 95\% Cl 2.88-7.46\%). The prevalence rates of RRT in 1989 and before group was the lowest, which was 1.56\% (95\% Cl 0-3.68\%). However, there was no significant correlation between the year of publication and the mortality of burn patients with RRT. Dialysis-requiring AKI in burn patients could increases the risk of chronic kidney disease progression and end-stage renal disease. About 35\% of RRT patients need to maintain haemodialysis temporarily, even if they survive and leave hospital.

Conclusions: The prevalence rate of RRT is about 6-8\%; approximately, one-third of burn patients with AKI need RRT. The prevalence rate of RRT increased over time, but the mortality did not change. The prevalence rates of RRT in Asian group was higher than that of European and North America group.

Keywords: renal replacement therapy, burn patients, acute kidney injury, prevalence, mortality, renal outcome, meta-analysis 


\section{INTRODUCTION}

Acute kidney injury (AKI) is one of the common complications of burn patients that seriously threatens the life of patients and increases the length of stay, intensive care unit (ICU) length of stay and treatment costs $(1,2)$. In 2010, metaanalysis reported that the prevalence of AKI in burn patients ranged from 16 to $26.6 \%$ (3), depending on the severity of the burns and on the definition of AKI. The prevalence of AKI in burn patients ranged from 18.4 to $47.4 \%$ with the RIFLE standard (2). Burn patients with AKI had a significantly increased risk of death. The mortality of burn patients with AKI was $16.95-100 \%$, significantly higher than that of their control group $(7-29.41 \%)(4-7)$.

However, the prevalence and mortality of renal replacement therapy (RRT) for burn patients are still unclear. A meta-analysis in 2010 conducted a subgroup analysis of the prevalence and mortality of RRT in burn AKI patients. The results showed that the prevalence of RRT was $3.2 \%$ in all burn patients and $27.1 \%$ in burn patients with AKI. The mortality of burn patients with RRT was as high as $80 \%$ [95\% confidence interval (CI) $72-$ 88.6\%] (3). Moreover, the updated meta-analysis of burn patients admitted to the ICU showed that the prevalence of RRT in all burn patients was $12 \%$, and the mortality was $74 \%$ (95\% CI 58 $87 \%$ ) (8). A recently published multicenter observational study showed that the mortality rate of RRT in severe burn patients has been reduced to about $50 \%$ (9). The mortality of burn patients with RRT was still very high. However, due to the different directions of attention, the literature of RRT for burn patients included in these studies is incomplete. At present, there is a lack of meta-analysis of RRT for burn patients. The primary aim of this study was to review incidence rate and mortality of RRT in burn patients. Second aims were to review RRT complications and renal outcome.

\section{METHODS}

This systematic review was conducted using the Preferred Reporting Items for Systematic Reviews and Meta-Analyzes and the Meta-Analysis of Observational Studies in Epidemiology guidelines $(10,11)$.

\section{Eligibility Criteria}

Studies on adult populations with burn injury, providing epidemiologic data on prevalence and mortality of RRT, were included. The adult ( $>16$ years of age) patients with burns covering $10 \%$ or more of the total body surface area (TBSA) were enrolled. Moreover, TBSA used in the subgroup analysis. Studies conducted only in patients with chemical or electrical burns were not included because of the different pathophysiologies. We excluded studies with a sample size of $<10$. Other blood purification techniques, such as plasma exchange (non-RRT), are not included in this study.

\section{Search Strategy}

We used the following terms for standard medical subject headings and free-text words: burn, burns, renal, kidney, kidney injury, kidney diseases, renal insufficiency, renal failure, and kidney failure. We also reviewed the references cited in all the studies selected for review. The search was performed in January 2020 and considered the period 1960-2019. The year of publication used in the subgroup analysis. An extensive search of literature published was conducted using the databases PubMed/MEDLINE, Embase, Science Citation Index (Web of Science), and the Cochrane Central Register of Controlled Trials (CENTRAL) database. Two searchers (D.ZY. and C.FK.) conducted the search independently. If one of the searchers thought that the article was appropriate, the study was selected.

\section{Study Selection}

Two reviews (D.ZY. and C.FK.) independently screened studies for eligibility according to study selection criteria. The inclusion criteria were randomized controlled trial (RCT), case-control and cohort studies. Cross-sectional studies were excluded because they cannot clearly identify the causal relationship between observed indicators and diseases. Only articles in English, Japanese or Chinese were included. Populations with pediatric patients, animal studies, case reports and reviews were excluded. Any disagreement between reviewers were resolved by consensus. RRTs included slow low-efficiency dialysis, intermittent haemodialysis (IHD), peritoneal dialysis (PD), and continuous renal replacement therapy (CRRT). We excluded the study of plasma exchange in burn patients because the mechanism and mode of treatment of plasma exchange are different from those of dialysis. We excluded the lack of mortality studies aimed at studying antibiotic pharmacokinetics in burn patients with RRT. We excluded the pre-existing comorbidity for RRT such as end-stage renal disease. For studies that gave multiple mortalities, we took the longest mortality, such as 28 , 60,90 , or in-hospital mortality.

\section{Study Quality}

We assessed risk of bias for RCTs using the Cochrane Collaboration's tool for assessing bias (12). We assessed risk of bias for case-control and cohort studies using the NewcastleOttawa Scale (NOS) (13). The NOS allocates nine points for quality of the selection (four items, four points), comparability (one item, two points), and outcome or exposure (three items, three points). Publication bias was assessed by creating and examining funnel plots. The robustness of the results was evaluated using sensitivity analyzes. Each study included in this review was assessed for quality as good (7-9), moderate (4-6), or poor $(\leq 3)$ based on scores.

\section{Data Extraction and Statistical Analysis}

Two independent reviewers (D.ZY. and C.FK.) extracted the following information from the included studies: title, author, year, journal, study design, nationality, sample size, definition of AKI, number of patients with or without AKI, number of patients with or without RRT, RRT details (modalities, device and manufacturer, dose, anticoagulants), and results (mortality of AKI patients, mortality of RRT patients). We also reported other outcomes (RRT complications, renal outcomelong-term dialysis, temporarily required dialysis, chronic kidney disease progress). 


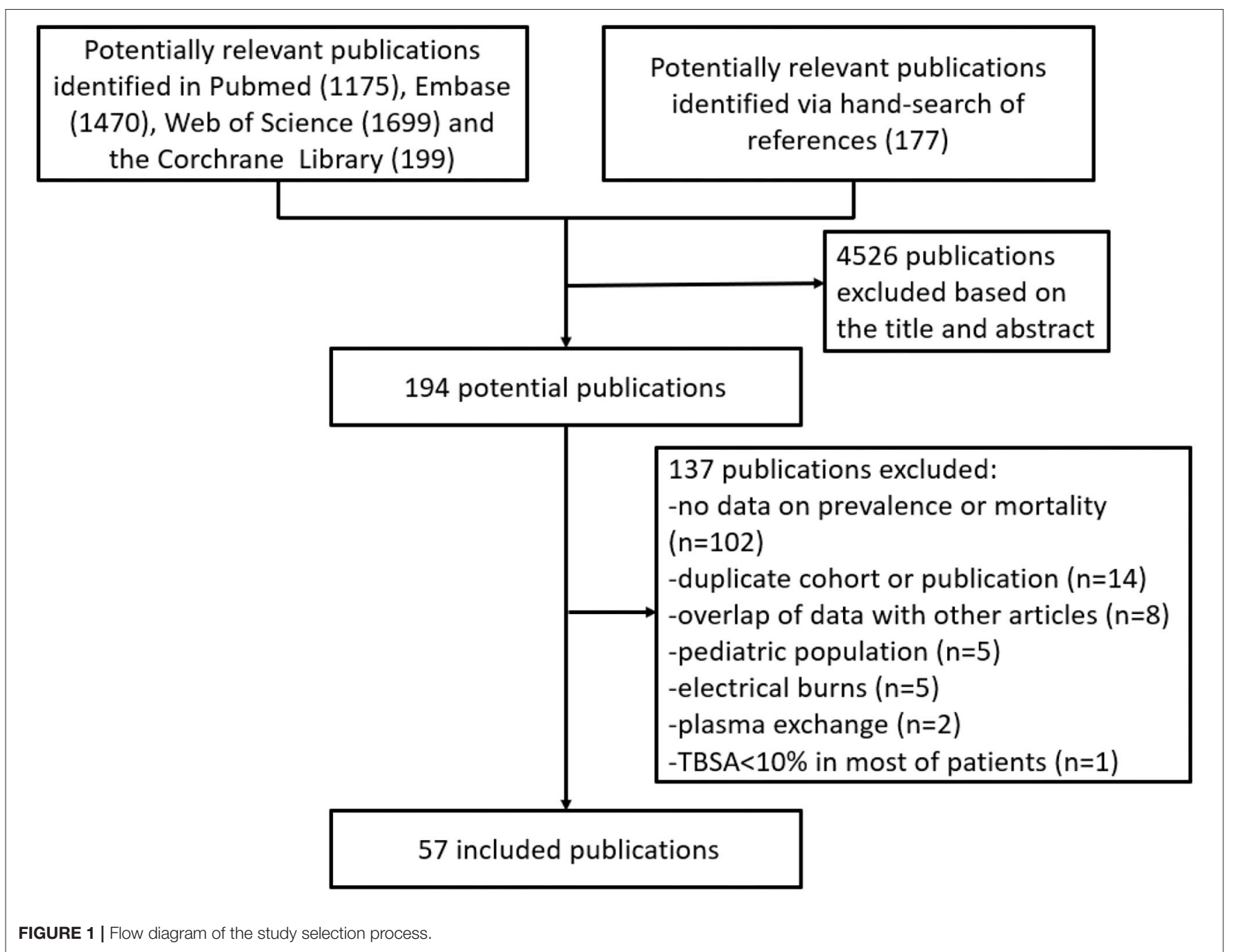

All ambiguities in data extraction were double-checked and resolved. Relative risks and 95\% confidence intervals were obtained using a random effects model. $I^{2}$ derived from the chi-squared test was used to evaluate the heterogeneity across the included studies. An $I^{2}<50 \%$ indicated that there was no significant heterogeneity (14). Sensitivity analysis was performed by sequentially removing each individual study. We assessed publication bias by constructing a funnel plot. Pearson or Spearman's correlation was used to analyze correlations. A twotailed $P$-value of $<0.05$ was considered statistically significant. All statistical analyzes were performed using Review Manager version 5.3, SPSS 24.0 and R 3.5.1 software were used for metaanalyzes of prevalence and mortality.

\section{RESULTS}

\section{Quality Assessment and Study Characteristics}

We screened and evaluated 4,720 studies, assessing 194 for eligibility. The selected 57 studies, including 27,437 patients, were enrolled in our analysis (Figure 1) (4-7, 9, 15-65). There were 4,345 burn patients with AKI and 1,754 burn patients with RRT. A total of $93.5 \%$ of the burn patients with RRT were AKI patients. Figure 1 shows a flow chart of the identification and selection of the studies.

The main features of these studies are shown in Table 1. Risk of bias is summarized in Supplementary Table 1 of the (cohort or case-control studies) and Supplementary Figure 1 of the (RCT studies). Among the 57 included studies, 22 were from North America (4, 9, 15, 16, 24, 26, 28, 30, 31, 33, 34, 40, 42-44, 48$50,54,59,61,62), 18$ were from Asia $(5,7,19,21-23,25,36-$ $38,41,46,47,51,52,58,64,67), 15$ were from European countries $(6,17,18,20,27,32,35,45,53,55-57,60,65,66)$, one was from South America (29), one was Africa (39). A total of 12 studies could not be used for analysis of the prevalence of RRT, seven of which only reported on RRT patients $(9,18,34,37,38,43$, $45)$, four of which were RCT studies $(40,41,51,52)$, and the remaining one of which were historical controls (44). Most of the 40 studies $(40 / 57)$ were retrospective cohort studies, but 12 were prospective cohort studies $(7,32,36,39,43,46,47,50,57,58,64$, $65)$, and 5 RCT studies $(40,41,51,52,56)$. 
TABLE 1 | Summary of the baseline characteristics of the studies included in the meta-analysis.

\begin{tabular}{|c|c|c|c|c|c|c|}
\hline Study & Study type & Sample size & AKI definition & $\begin{array}{c}\text { AKI } \\
\text { numbers }\end{array}$ & $\begin{array}{c}\text { RRT } \\
\text { numbers }\end{array}$ & $\begin{array}{l}\text { RRT mortality } \\
(\%)\end{array}$ \\
\hline Akers et al. (42) & Retrospective cohort & 171 & $\geq 0.5 \mathrm{mg} / \mathrm{dL} \mathrm{SCr}$ increase & 38 & 33 & $19(57.58)$ \\
\hline Bechir et al. (56) & Randomized controlled trial & 45 & Dialysis & 12 & 12 & NA \\
\hline Boucher et al. (43) & Prospective cohort & 10 & AKIN criteria & 9 & 10 & $3(30)$ \\
\hline Chun et al. (58) & Prospective cohort & 76 & AKIN criteria & 32 & 20 & $19(95)$ \\
\hline Chung et al. (44) & Retrospective cohort & 102 & RIFLE classification & 34 & 18 & $10(55.56)$ \\
\hline Chung et al. (40) & Randomized controlled trial & 37 & $\begin{array}{l}\text { Oliguria }(<20 \mathrm{ml} / \mathrm{h}) \text { for }>24 \mathrm{~h} \text { or an increase } \\
\mathrm{Scr}>2 \mathrm{mg} / \mathrm{dl} \text { in males or }>1.5 \mathrm{mg} / \mathrm{dl} \text { in females } \\
\text { over a period of }<4 \text { days }\end{array}$ & 37 & 37 & $23(62.16)$ \\
\hline Damkat-Thomas et al. (16) & Retrospective cohort & 41 & RIFLE classification & 17 & 5 & $2(40)$ \\
\hline Davies et al. (17) & Retrospective cohort & 1,064 & NA & 28 & 25 & $22(88)$ \\
\hline Demsey et al. (54) & Retrospective cohort & 151 & AKIN criteria & 64 & 18 & 7 (38.89) \\
\hline Depret et al. (60) & Retrospective cohort & 87 & KDIGO criteria & 55 & 21 & NA \\
\hline Gille et al. (18) & Retrospective cohort & 18 & NA & 18 & 18 & $2(11.11)$ \\
\hline Haberal et al. (19) & Retrospective cohort & 915 & NA & 19 & 19 & 15 (78.95) \\
\hline Hladik et al. (45) & Retrospective cohort & 40 & NA & 10 & 40 & $28(70)$ \\
\hline Holm et al. (20) & Retrospective cohort & 328 & $\begin{array}{l}\text { Scr }>2.0 \mathrm{mg} / \mathrm{dl} \text { (with rising tendency) } \\
\text { combined with a blood urea nitrogen level } \\
>200 \mathrm{mg} / \mathrm{dl} \text { or in patients with anuria or oliguria } \\
\text { (urine volume }<400 \mathrm{ml} / 24 \mathrm{~h} \text { ) }\end{array}$ & 48 & 48 & $41(85.42)$ \\
\hline Kuo et al. (23) & Retrospective cohort & 301 & AKIN criteria & 34 & 28 & NA \\
\hline Kym et al. (47) & Prospective cohort & 85 & RIFLE classification & 48 & 22 & NA \\
\hline Leblanc et al. (24) & Retrospective cohort & 970 & NA & 16 & 16 & $13(81.25)$ \\
\hline Liu et al. (52) & Randomized controlled trial & 41 & NA & NA & 20 & $7(35)$ \\
\hline Liu (25) & Retrospective cohort & 6,050 & NA & 53 & 15 & $8(53.33)$ \\
\hline Lopes et al. (53) & Retrospective cohort & 126 & Doubling of baseline Scr & 32 & 11 & NA \\
\hline Mariano et al. (55) & Retrospective cohort & 548 & NA & 98 & 70 & 50 (71.43) \\
\hline Mason et al. (26) & Retrospective cohort & 330 & $\mathrm{Scr}>1.5 \mathrm{mg} / \mathrm{dL}$ & 48 & 37 & NA \\
\hline Munoz et al. (6) & Retrospective cohort & 840 & KDIGO criteria & 466 & 34 & NA \\
\hline Mustonen and Vuola (27) & Retrospective cohort & 238 & $\begin{array}{l}\text { Scr }>120 \text { umol/L ( } 1.4 \mathrm{mg} / \mathrm{dL}) \text {; for chronic renal } \\
\text { insufficiency patients, } 2 \text {-fold rise in Scr or Scr } \\
\text { rose }>100 \mu \mathrm{mol} / / \text { during } 1 \text { day }\end{array}$ & 93 & 32 & $20(62.5)$ \\
\hline Peng et al. (51) & Randomized controlled trial & 20 & NA & NA & 10 & $1(10)$ \\
\hline Planas et al. (48) & Retrospective cohort & 29 & $\begin{array}{l}\text { Scr level above initial values to a level equal to } \\
\text { or }>1.5 \mathrm{mg} / \mathrm{dL}\end{array}$ & 11 & 3 & $2(66.67)$ \\
\hline Pronina et al. (28) & Retrospective cohort & 1,405 & AKIN or RIFLE criteria & 53 & 21 & 7 (33.33) \\
\hline Queiroz et al. (29) & Retrospective cohort & 293 & $\begin{array}{l}\text { An elevation in baseline serum creatinine } \\
\text { greater than or equal to } 50 \% \text { from baseline }\end{array}$ & 77 & 52 & NA \\
\hline Rakkolainen et al. (66) & Retrospective cohort & 187 & $\mathrm{Scr} \geq 120 \mathrm{umol} / \mathrm{L}(1.4 \mathrm{mg} / \mathrm{dll})$ & 51 & 21 & $9(42.86)$ \\
\hline
\end{tabular}


TABLE 1 | Continued

\begin{tabular}{|c|c|c|c|c|c|c|}
\hline Study & Study type & Sample size & AKI definition & $\begin{array}{c}\text { AKI } \\
\text { numbers }\end{array}$ & $\begin{array}{c}\text { RRT } \\
\text { numbers }\end{array}$ & $\begin{array}{c}\text { RRT mortality } \\
(\%)\end{array}$ \\
\hline Ren et al. (64) & Prospective cohort & 58 & KDIGO criteria & 11 & 5 & $4(80)$ \\
\hline Sabry et al. (39) & Prospective cohort & 40 & $\begin{array}{l}\mathrm{Scr}>2 \mathrm{mg} / \mathrm{dL} \text { and blood urea nitrogen }>25 \\
\mathrm{mg} / \mathrm{dL}\end{array}$ & 9 & 4 & $2(50)$ \\
\hline Saffle et al. (30) & Retrospective cohort & 529 & $\mathrm{Scr}>132.6 \mathrm{umol} / \mathrm{L}(1.5 \mathrm{mg} / \mathrm{dL})$ & 143 & 5 & $5(100)$ \\
\hline Sanchez-Sanchez et al. (65) & Prospective cohort & 165 & RIFLE classification & 32 & 15 & $14(93.33)$ \\
\hline Schneider et al. (49) & Retrospective cohort & 220 & RIFLE classification & 103 & 25 & NA \\
\hline Sen et al. (50) & Prospective cohort & 30 & RIFLE classification & 14 & 3 & NA \\
\hline Soltani et al. (31) & Retrospective cohort & 1,125 & NA & 38 & 33 & $23(69.7)$ \\
\hline Steinvall et al. (32) & Prospective cohort & 127 & RIFLE classification & 31 & 4 & $3(75)$ \\
\hline Stewart et al. (33) & Retrospective cohort & 1,967 & AKIN criteria & 640 & 70 & $49(70)$ \\
\hline Tang et al. (67) & Retrospective cohort & 157 & AKIN criteria & 89 & 82 & NA \\
\hline Tremblay et al. (34) & Retrospective cohort & 12 & NA & 12 & 12 & $6(50)$ \\
\hline Witkowski etal. (35) & Retrospective cohort & 225 & $\begin{array}{l}\text { Decrease in GFR of }<60 \mathrm{ml} / \mathrm{min} \text { at admission, } \\
\text { decrease in GFR of more than } 75 \% \text { compared } \\
\text { to baseline or decrease in the daily diuresis of } \\
<500 \mathrm{ml} \text { for at least } 24 \mathrm{~h}\end{array}$ & 135 & 9 & $9(100)$ \\
\hline Yang et al. (36) & Prospective cohort & 90 & RIFLE classification & 55 & 22 & $17(77.27)$ \\
\hline Yim et al. (7) & Prospective cohort & 97 & AKIN criteria & 40 & 23 & NA \\
\hline Yoon et al. (37) & Retrospective cohort & 84 & RIFLE classification & 84 & 84 & $71(84.5)$ \\
\hline Yoon et al. (38) & Retrospective cohort & 216 & AKIN criteria & 190 & 216 & $176(81.48)$ \\
\hline You (41) & Randomized controlled trial & 82 & KDIGO stage 3 & 9 & 41 & $11(26.83)$ \\
\hline
\end{tabular}

AKI, acute kidney injury; RRT, renal replacement therapy; NA, not available; Scr, serum creatine; GFR, glomerular filtration rate.

TABLE 2 | The prevalence of RRT in burn patients with different diagnostic criteria.

\begin{tabular}{|c|c|c|c|c|c|c|}
\hline Diagnosis & N. of Trials & Patients & $I^{2}(\%)$ & $P$ & Prevalence (\%) & $95 \% \mathrm{Cl}$ \\
\hline All burn patients & 45 & 22,726 & 96 & $<0.01$ & 8.34 & $7.18-9.5$ \\
\hline RRT of AKI patients & 38 & 3,556 & 98 & $<0.01$ & 37.05 & $29.85-44.24$ \\
\hline $\mathrm{ICU}$ & 22 & 5,480 & 90 & $<0.01$ & 11.14 & $8.86-13.42$ \\
\hline RIFLE classification & 11 & 596 & 78 & $<0.01$ & 28.85 & $21.0-36.69$ \\
\hline AKIN classification & 9 & 1,180 & 98 & $<0.01$ & 43.96 & $28.0-59.91$ \\
\hline
\end{tabular}

Cl, confidence interval; RRT, renal replacement therapy; AKI, acute kidney disease; ICU, intensive care unit.

\section{Prevalence and Mortality of RRT in Burn Patients}

We analyzed 45 literatures that reported the prevalence of RRT in burn patients (Table 2) $(4-7,15,16,19-33,35,36$, $39,42,46-50,53-62,64-68)$. The prevalence rates of RRT were $8.34 \%(95 \%$ CI $7.18-9.5 \%)$ in all burn patients and $37.05 \%$ (95\% CI 29.85-44.24\%) in AKI patients. The prevalence of RRT among burn patients in the ICU was $11.14 \%(95 \%$ CI $8.86-13.42 \%)(4-7,16,22,27,29,31,36,42,46,47$, $50,54,56,57,59,60,62,65,66)$. A total of 25 studies with RIFLE, AKIN and KDIGO as AKI diagnostic criteria after 2004 were analyzed $(4,6,7,16,21-23,28,32,33,35$, $36,46,47,49,50,54,58-62,64,65,67)$. The prevalence of RRT in these burn patients was $30.03 \%$ (95\% CI $23.88-$ $36.18 \%)$.
In order to balance the bias of small sample study $(n<100)$, we did subgroup analysis for the study with sample size $>100$ (Supplementary Table 2). The prevalence rates of RRT in these studies were $6.86 \%$ (95\% CI 5.70-8.03\%), which was lower than that of sample size $<100$ group (17.61\%, 95\% CI 13.39-21.82\%). The prevalence rates of RRT in sample size $\geq 1,000$ group were $2.52 \%$ (95\% CI $1.02-4.02 \%$ ). However, one third of the studies in sample size $\geq 1,000$ group were from the $1980 \mathrm{~s}$, and the prevalence rates of RRT may be reduced because RRT was still in its infancy at that time.

The TBSA was used for subgroup analysis $(\geq 10 \%, \geq 20 \%$, $\geq 30 \%$ or second and third degree burns $>10 \%, \geq 40 \%$ or second and third degree burns $>20 \%$ ). The results showed that, with the increase of TBSA, the prevalence of RRT may have the increasing trend (Supplementary Table 3). The prevalence rates of RRT in 
TABLE 3 | The mortality of RRT in burn patients with different diagnostic criteria.

\begin{tabular}{|c|c|c|c|c|c|c|}
\hline Diagnosis & N. of Trials & Patients & $I^{2}(\%)$ & $\boldsymbol{P}$ & RRT mortality (\%) & $95 \% \mathrm{Cl}$ \\
\hline Summary of all literatures & 41 & 1,342 & 90 & $<0.01$ & 65.52 & $58.41-72.64$ \\
\hline ICU & 20 & 797 & 85 & $<0.01$ & 62.7 & $53.7-71.7$ \\
\hline RIFLE classification & 9 & 185 & 77 & $<0.01$ & 70.08 & $56.4-83.75$ \\
\hline AKIN classification & 7 & 370 & 90 & $<0.01$ & 66.73 & $52.01-81.45$ \\
\hline KDIGO classification & 5 & 283 & 81 & $<0.01$ & 55.29 & $39.46-71.12$ \\
\hline Summary of RIFLE, AKIN, KDIGO & 20 & 811 & 90 & $<0.01$ & 67.16 & $57.40-76.93$ \\
\hline
\end{tabular}

$R R T$, renal replacement therapy; $\mathrm{Cl}$, confidence interval; ICU, intensive care unit.

TBSA $\geq 20 \%$ group was $14.33 \%$ (95\% CI $10.10-18.57 \%$ ), which was higher than that of TBSA $\geq 10 \%$ group $(6.4 \%, 95 \%$ CI $4.12-$ $8.69 \%)$. The prevalence rates of RRT in TBSA $\geq 40 \%$ group was the highest, which was $14.66 \%$ (95\% CI 5.22-24.09\%).

In the study location subgroup analysis (Supplementary Table 4), the prevalence rates of RRT in Asian group was $12.75 \%$ (95\% CI 9.50-16.00\%), which was higher than that of European (10.45\%, 95\% CI 7.30-13.61\%) and North America group (5.61\%, 95\% CI 4.27-6.95\%).

Moreover, we analyzed the results of 41 studies that reported RRT mortality in burn patients (Table 3 ). The mortality of all burn patients with RRT was $65.52 \%$ (95\% CI 58.41-72.64\%) (4, 5, $9,15-20,22,24,25,27,28,30-46,48,51,52,54,55,58,59,64-66)$. The mortality of patients with RRT in ICU was $62.7 \%$ (95\% CI $53.7-71.7 \%)(4,5,9,16,22,27,31,36,38,40-46,54,59,65,66)$. The results of 20 studies with RIFLE, AKIN, and KDIGO as AKI diagnostic criteria showed that the mortality of RRT in burn patients was $67.16 \%$ (95\% CI 57.40-76.93\%) (4, 9, 16, 22, 28, 32, $33,35-38,41,43,44,46,54,58,59,64,65)$. Three studies reported deaths in all burn patients undergoing $\operatorname{RRT}(5,30,35,42)$. According to different mortality categories, the mortalities of 14 days, 28 days and 60 days ranged from 30 to $50 \%$, while those of ICU and hospital were 56.98 and $68.89 \%$, and overall mortality further increased to $75.24 \%$ (Supplementary Table 5).

According to the three diagnostic criteria of RIFLE, AKIN, and KDIGO, the prevalence of RRT was KDIGO $<$ RIFLE $<$ AKIN, and that of mortality was KDIGO $<$ AKIN $<$ RIFLE. The prevalence of RRT was $15.97 \%$ (95\% CI 9.51-22.44\%) and that of mortality was $55.29 \%$ (95\% CI 39.46-71.12\%) in the six literatures with KDIGO classification as the diagnostic standard, which was lower than other AKI diagnostic standards.

There was no significant correlation $(r=-0.224, P=0.159)$ between the year of publication and the mortality of burn patients with RRT (Supplementary Figure 2). According to the year of publication, the patients were divided into four subgroups (Supplementary Figure 3) from 2010 to 2020, 2000 to 2009, 1990 to 1999,1989 and before. The mortality of the 2010-2020 group was $60.42 \pm 25.35 \%$, that of the 2000-2009 group was $61.55 \pm$ $23.29 \%$, that of the 1990-1999 group was $87.33 \pm 8.44 \%$, and that of the 1989 and before group was $63.52 \pm 25.05 \%$. There was no significant difference between groups $(P=0.139)$. After 2010, three studies still reported that the mortality of RRT patients was more than $90 \%(35,58,65)$. The prevalence rates of RRT in 2010-2019 group was $12.22 \%$ (95\% CI 10.09-14.35\%), which was higher than that of 2009-2000 group (5.17\%, 95\% CI $2.88-$ $7.46 \%)$. The prevalence rates of RRT in 1989 and before group was the lowest, which was $1.56 \%$ (95\% CI 0-3.68\%). The results showed that the prevalence rate of RRT increased over time (Supplementary Table 6).

\section{RRT-Related Adverse Reactions}

Nine articles reported the incidence of RRT-related adverse reactions. The total incidence was $28.77 \%(63 / 229)(18,20,24,25$, $27,34,40,41,51)$, including thrombocytopenia $0.44 \%(1 / 229)$, bleeding $10.92 \%$ (25/229), thromboembolism $1.75 \%(4 / 229)$, secondary infection $9.61 \%(22 / 229)$, electrolyte disorder $2.62 \%$ (6/229), and imbalance syndrome $0.44 \%$ (1/229). Among them, only Chung 2017 reported six patients with electrolyte disorder. Other literatures may not mention the occurrence of electrolyte disorder due to certain concerns, which may underestimate the prevalence of electrolyte disorder. A total of 16 patients with PD were reported in 9 articles; most of these patients were from Liu 1986 (25). Among the 16 patients, 1 had "unbalanced syndrome" and improved after stopping dialysis; 4 had abdominal infection, 3 survived, and one changed to haemodialysis and ultimately died. Considering the immature technology at that time, the incidence of $\mathrm{PD}$ adverse reactions may be overestimated.

\section{Renal Outcome}

A recent study found an odds of dialysis of 2.40 in burn patients who developed AKI compared with the general Finnish population (69). Eleven studies followed up the long-term renal outcomes of burn patients who survived RRT (9, 16, 18, 24, $27,31,33,34,40,50,54)$. A total of 184 patients survived after RRT; $64.13 \%$ of them (118/184) were dialysis-independent after discharge, 25\% (46/184) needed temporary required dialysis, and $10.87 \%(20 / 184)$ needed long-term dialysis (more than 6 months after discharge). Thalji 2017 found that 1 year after burn, the proportion of chronic dialysis in non-AKI patients was $0.33 \%(56 / 16985)$, significantly lower than that in patients with AKI, which was $4.58 \%(26 / 568)(70)$. The proportion of severe chronic kidney disease (CKD, defined as stage 3-5) in nonAKI patients $(0.71 \%)$ was also lower than those in AKI patients (5.81\%) (70). Gille reported that 3 of the 16 surviving burn patients undergoing CRRT had CKD progression (glomerular filtration rate $($ GFR $)<45 \mathrm{ml} / \mathrm{min} .1 .73 \mathrm{~m}^{2}$, CKD 3b) (18.75\%) (18). Two patients had slightly impaired GFR $(<90 \mathrm{ml} / \mathrm{min} .1 .73$ 
$\mathrm{m}^{2}$, CKD 2) before the burn trauma. One patient had normal GFR (18).

\section{DISCUSSION}

Acute kidney injury is one of the common complications in burn patients. The incidence of AKI varied from 16\% to 26.6\% according to the definition of AKI in different populations (3). The incidence of AKI in burn ICUs was 38\% (30-46\%) (8). RRT was often needed by some severe burn patients with AKI. According to the subgroup analysis in the previous meta-analysis of burn patients with AKI, the proportion of all burn patients requiring RRT was $\sim 3 \%$ (3). The proportion of burn patients admitted to the ICU was $12 \%(8-16 \%)(8)$, and the mortality was $74 \%$ (95\% CI 58-87\%) (3). A recently published multicenter observational study showed that the mortality rate of RRT in severe burn patients has been reduced to about 50\% (9). The mortality of burn patients with RRT was still very high. Such high mortality rates were the reasons we wanted to conduct a metaanalysis of RRT in burn patients. A total of 27,437 burn patients were enrolled in this study from 57 literatures from 1979 to 2019. The results showed that the prevalence rates of RRT were $8.34 \%$ (95\% CI 7.18-9.5\%) in all burn patients and 37.05\% (95\% CI 29.85-44.24\%) in AKI patients. These data are higher than those reported in the subgroup of previous studies $(3,8)$. Due to the different purposes of previous studies, the number of RRT studies included in previous studies was significantly lower than that of this study.

The study of small sample size may enlarge the observation effect, which was first described by Sterne et al. (71). Small trials are more likely to report larger beneficial effects than large trials in critical care medicine (72). This study also found that compared with the large sample size study $(n \geq 100)$, the small sample size study may significantly enlarge the observation effect, that is, the prevalence rates of RRT. However, since the prevalence rates of RRT is not high in all burn patients, and some small sample size studies can provide more information on mortality, adverse reactions and renal outcome in RRT patients, we did not exclude small sample study, but instead, we used subgroup analysis to list them separately.

With the increase of TBSA, the risk of AKI is greater, and the risk of RRT may also be greater. High TBSA was a risk factor for AKI in burn patients (8). Our results showed that, with the increase of TBSA, the prevalence rates of RRT may have the increasing trend. The prevalence rates of RRT in TBSA $\geq 40 \%$ group was the highest. In a retrospective study of the aluminum dust explosion accident in Kunshan factory, 157 patients with severe burns were included, with an average TBSA more than $90 \%$. In this study, the incidence of AKI was $56.7 \%$, while the prevalence rates of RRT was $52.2 \%$ (67). In the study location subgroup analysis, the prevalence rates of RRT in Asian group was $12.75 \%$, which was higher than that of European and North America group. The reason for the increased the prevalence rates of RRT in Asian group may be closely related to the large number of small samples studies (about 50\%, 6/13) and the large TBSA of patients (TBSA $\geq 40 \%$ goup, $2 / 5$ ).
With the improvement and popularization of RRT, more and more severe burn patients with AKI can be treated with RRT. Our results showed that with the progress of the times, the prevalence rates of RRT in burn patients is gradually increasing from $<2 \%$ before 1980 s to $12.22 \%$ now. Before CRRT was popularized, some severe burn patients with AKI were unable to tolerate IHD because of hemodynamic compromise. Chung et al. reported in 2008 that their center started CRRT in November 2005. Compared with the CRRT group, none of the 16 patients in the consecutive historical control group matched with TBSA and injury severity score were placed on haemodialysis (44). In Chinese mainland, only 15 of 6,050 burn patients underwent RRT in the 1980s, and most of them were PD. About $1 / 4$ of the patients receiving PD developed abdominal infection (25). In 2012, the number rose to $6.31 \%$, and all of them received CRRT treatment (21). Moreover, economic reasons may also affect whether burn patients start RRT. A survey of nephrologists and critical care physicians in 189 different hospitals in China showed that one of the reasons prohibiting patients from getting RRT were high therapy costs (73). With the development of economy and the improvement of medical insurance reimbursement policy in recent years, the prevalence rate of RRT in severe burn patients with AKI may also increase. CRRT could make more severe burn patients with an indication for RRT and hemodynamic instability have the opportunity received RRT treatment. However, RCT and meta-analysis studies in critically ill patients did not find that CRRT had a survival benefit advantage compared with IHD and PD in hemodynamic stable patients $(74,75)$. There was no significant correlation between the year of publication and the mortality of burn patients with RRT in this study. Patients in the 1980 and 1990 groups received peritoneal dialysis or haemodialysis. Compared with the 1989 and before group and 1990-1999 group (received IHD or PD), most patients in the 2010-2020 group received CRRT, but there was no significant difference in mortality between groups.

RIFLE (76), AKIN (77) and KDIGO (78) are three commonly used AKI grading standards after 2004. The KDIGO diagnostic standard proposed in 2012 had been reported to improve the early diagnosis of kidney injury $(59,79)$ and to reduce the missed diagnosis rate (80), which was conducive to the early diagnosis and treatment of AKI. Our results showed that, compared with RIFLE and AKIN, the prevalence and mortality of RRT in KDIGO were relatively low. We speculate that early diagnosis and early treatment may help some burn patients with AKI avoid further deterioration of renal function, reduce the need for dialysis, and improve the prognosis of patients. Ren et al., defined AKI according to KDIGO guidelines by $48 \mathrm{~h}$ after admission. That prospective study reported $11.2 \%$ (11/95) AKI and only $35.4 \%$ mortality in the AKI group (64).

AKI in burn patients not only increases mortality (81), but also increases the risk of CKD progression and end-stage renal disease $(69,70)$. When severe burn patients have dialysis-requiring AKI, $\sim 35 \%$ of the patients need to maintain haemodialysis temporarily, even if they survive and leave the hospital. Among them, $10 \%$ of the surviving patients need haemodialysis for more than half a year. Therefore, for burn AKI or dialysis-requiring AKI survivors, it is recommended to monitor the renal function 
regularly within 1 year after discharge and to avoid the use of nephrotoxic drugs, excessive diuresis, and diarrhea (82), to reduce the progress of $\mathrm{CKD}$ and to avoid the recurrence of AKI.

This systematic review has several limitations. First, there was significant heterogeneity in most results of RRT prevalence and mortality in this study. The clinical heterogeneity of this study may be due to the differences in the study population, RRT modalities and the end-point indicators observed in the study. The inclusion and exclusion criteria were different among different studies. There were controversies on modalities, timing, and dosage of RRT, and the standards reported in different literatures are not the same. Outcome variables, such as mortality, also varied from study to study. Although we conducted a series of subgroup analyzes on AKI diagnostic criteria, ICU, different mortality criteria, TBSA, sample size, study location, and publication year, the results still showed heterogeneity. Because we were unable to obtain the original data for each patient, we cannot completely control the above confounding factors. Therefore, we used the random effect model to analyze the results. Second, we only included documents in English, Japanese and Chinese, and there may be omissions in documents reported in other languages, such as Russian. There was no literature from Russia in the studies we included. However, 57 articles and nearly 30,000 burn patients from five continents were included in this meta-analysis, most of which were in North America, Asia, and Europe. The inclusion of a large number of literatures and patients can ensure that the results of this study were well-representative, especially in North America, Asia, and Europe. Third, this study did not analyze the starting time of RRT for burn patients with AKI. At present, the timing of RRT for critically ill patients is still controversial. At the beginning of this study, we plan to analyze the timing of RRT in burn patients. However, even if 57 articles were included, there is still a lack of head-to-head study on the starting time of RRT for burn patients with AKI. There was only one cohort study that was divided into groups according to the AKI level of patients at the beginning of CRRT. The early CRRT group was defined according to the patients who started CRRT at the risk stage of the RIFLE criteria. The results showed there were no significant differences in mortality by the severity of AKI at the time of CRRT initiation (37). We suggest that more head-to-head cohort studies or RCT studies can be designed in the future regarding the timing of RRT in burn patients. Finally, the current study is not registered, and there may be a small deviation, but we still strictly follow the steps of systematic review.

Our meta-analysis had a number of strengths. In this study, 57 articles from 1979 to 2019 were included, involving nearly 30,000 burn patients. It has obvious representative advantages for the prevalence and mortality of RRT for burn patients with

\section{REFERENCES}

1. Knowlin LT, Purcell L, Cairns BA, Charles AG. Burn injury mortality in patients with preexisting and new onset renal high statistical variability. Due to the large number of included literatures, we were able to conduct a series of subgroup analyzes on AKI diagnostic criteria, ICU, different mortality criteria, TBSA, sample size, study location, and publication year. As a result of a series of subgroup analysis, we found that The prevalence rate of RRT increased with TBSA and time. The prevalence rates of RRT in Asian group was higher than that of European and North America group.

\section{CONCLUSIONS}

The prevalence rate of RRT is about 6-8\%; approximately, onethird of burn patients with AKI need RRT. The prevalence rate of RRT increased over time, but the mortality did not change. The prevalence rates of RRT in Asian group was higher than that of European and North America group.

\section{DATA AVAILABILITY STATEMENT}

The original contributions presented in the study are included in the article/Supplementary Material, further inquiries can be directed to the corresponding authors.

\section{AUTHOR CONTRIBUTIONS}

GC and JL contributed to the conception and design of the study. $\mathrm{ZD}$ and FC selected the studies, extracted the data, performed the statistical analyzes, and data presentation. ZD evaluated the study quality. The manuscript was drafted by ZD, with assistance by FC and JL, and the manuscript was critically revised by XC and GC. All authors contributed to the article and approved the submitted version.

\section{FUNDING}

This study was supported by National Key R\&D Program of China (2018YFA0108803), Logistics research project (BLB19J009), Science and Technology Project of Beijing, China (D181100000118004, Z161100000516225, and D1771100002817002), and Natural Science Foundation of China (NSFC) (81600548 and 81670694). They have no role in study design, data collection, data analysis, data interpretation, or writing of the report.

\section{SUPPLEMENTARY MATERIAL}

The Supplementary Material for this article can be found online at: https://www.frontiersin.org/articles/10.3389/fmed. 2021.708533/full\#supplementary-material

disease. Am J Surg. (2018) 215:1011-5. doi: 10.1016/j.amjsurg.2018. 02.027

2. Wu G, Xiao Y, Wang C, Hong X, Sun Y, Ma B, et al. Risk factors for acute kidney injury in patients with burn injury: a 
meta-analysis and systematic review. J Burn Care Res. (2017) 38:271-82. doi: 10.1097/BCR.0000000000000438

3. Brusselaers N, Monstrey S, Colpaert K, Decruyenaere J, Blot SI, Hoste EA. Outcome of acute kidney injury in severe burns: a systematic review and metaanalysis. Int Care Med. (2010) 36:915-25. doi: 10.1007/s00134-010-1861-1

4. Coca SG, Bauling P, Schifftner T, Howard CS, Teitelbaum I, Parikh CR. Contribution of acute kidney injury toward morbidity and mortality in burns: a contemporary analysis. Am J Kidney Dis. (2007) 49:51723. doi: 10.1053/j.ajkd.2006.12.018

5. Kim GH, Oh KH, Yoon JW, Koo JW, Kim HJ, Chae DW, et al. Impact of burn size and initial serum albumin level on acute renal failure occurring in major burn. Am J Nephrol. (2003) 23:55-60. doi: 10.1159/000066299

6. Martins Munoz J, Nin N, Penuelas O, Muriel A, Abril J, Lorente Balanza JA. Acute kidney injury in critically ill burned patients is independently associated with increased mortality. Nephrol Dial Transpl. (2017) 32:528. doi: 10.1093/ndt/gfx167.MP274

7. Yim H, Kym D, Seo DK, Yoon J, Yang HT, Lee J, et al. Serum cystatin C and microalbuminuria in burn patients with acute kidney injury. Eur J Clin Invest. (2015) 45:594-600. doi: 10.1111/eci.12452

8. Folkestad T, Brurberg KG, Nordhuus KM, Tveiten CK, Guttormsen AB, Os I, et al. Acute kidney injury in burn patients admitted to the intensive care unit: a systematic review and meta-analysis. Crit Care. (2020) 24:2. doi: 10.1186/s13054-019-2710-4

9. Chung KK, Coates EC, Hickerson WL, Arnold-Ross AL, Caruso DM, Albrecht $M$, et al. Renal replacement therapy in severe burns: a multicenter observational study. J Burn Care Res. (2018) 39:101721. doi: $10.1093 /$ jbcr/iry036

10. Moher D, Liberati A, Tetzlaff J, Altman DG, Group P. Preferred reporting items for systematic reviews and meta-analyses: the PRISMA statement. BMJ. (2009) 339:b2535. doi: 10.1136/bmj.b2535

11. Stroup DF, Berlin JA, Morton SC, Olkin I, Williamson GD, Rennie D, et al. Meta-analysis of observational studies in epidemiology: a proposal for reporting. Meta-analysis of observational studies in epidemiology (MOOSE) group. JAMA. (2000) 283:2008-12. doi: 10.1001/jama.283. 15.2008

12. Higgins JP, Altman DG, Gotzsche PC, Juni P, Moher D, Oxman AD, et al. The cochrane collaboration's tool for assessing risk of bias in randomised trials. BMJ. (2011) 343:d5928. doi: 10.1136/bmj.d5928

13. Wells GA, Shea B, O'Connell D, Peterson J, Welch V, Losos M, et al. NewcastleOttawa Scale (NOS) for Assessing the Quality of Nonrandomised Studies in Meta-Analyses. (2014). Available online at: http://www.ohri.ca/programs/ clinical_epidemiology/oxford.asp (accessed February 2, 2020).

14. Higgins JP, Thompson SG, Deeks JJ, Altman DG. Measuring inconsistency in meta-analyses. BMJ. (2003) 327:557-60. doi: 10.1136/bmj.327.7414.557

15. Chrysopoulo MT, Jeschke MG, Dziewulski P, Barrow RE, Herndon DN. Acute renal dysfunction in severely burned adults. J Trauma. (1999) 46:1414. doi: 10.1097/00005373-199901000-00024

16. Damkat-Thomas L, Black CE, Bedi A. Acute kidney injury and the burned patient: progression and outcomes. Burns. (2011) 37:175-6; author reply 6-7. doi: 10.1016/j.burns.2010.06.013

17. Davies DM, Pusey CD, Rainford DJ, Brown JM, Bennett JP. Acute renal failure in burns. Scand J Plast Reconstr Surg. (1979) 13:18992. doi: 10.3109/02844317909013054

18. Gille J, Sablotzki A, Malcharek M, Raff T, Mogk M, Parentin T. Regional citrate anticoagulation for continuous renal replacement therapy in severe burns-a retrospective analysis of a protocol-guided approach. Burns. (2014) 40:1593-601. doi: 10.1016/j.burns.2014.01.028

19. Haberal M, Ozdemir A, Bayraktar U, Oner Z, Bilgin N, Collini FJ. Gastrointestinal and renal complications in burned patients. Eur J Plas Surg. (1993) 16:17-21. doi: 10.1007/BF00192700

20. Holm C, Horbrand F, von Donnersmarck GH, Muhlbauer W. Acute renal failure in severely burned patients. Burns. (1999) 25:171-8. doi: 10.1016/S0305-4179(98)00144-2

21. Hu JY, Meng XC, Han J, Xiang F, Fang YD, Wu J, et al. Relation between proteinuria and acute kidney injury in patients with severe burns. Crit Care. (2012) 16:R172. doi: 10.1186/cc11649

22. Kuo G, Yang SY, Chuang SS, Fan PC, Chang CH, Hsiao YC, et al. Using acute kidney injury severity and scoring systems to predict outcome in patients with burn injury. J Formos Med Assoc. (2016) 115:104652. doi: 10.1016/j.jfma.2016.10.012

23. Kuo G, Lee CC, Yang SY, Hsiao YC, Chuang SS, Chang SW, et al. Hyperphosphatemia is associated with high mortality in severe burns. PLoS ONE. (2018) 13:e0190978. doi: 10.1371/journal.pone.0190978

24. Leblanc M, Thibeault Y, Querin S. Continuous haemofiltration and haemodiafiltration for acute renal failure in severely burned patients. Burns. (1997) 23:160-5. doi: 10.1016/S0305-4179(96)00085-X

25. Liu YL. [Experiences in the treatment of 53 cases of major burns with acute renal failure]. Zhonghua Zheng Xing Shao Shang Wai Ke Za Zhi. (1986) 2:103-5.

26. Mason SA, Nathens AB, Finnerty CC, Gamelli RL, Gibran NS, Arnoldo $\mathrm{BD}$, et al. Hold the pendulum: rates of acute kidney injury are increased in patients who receive resuscitation volumes less than predicted by the parkland equation. Ann Surg. (2016) 264:1142-7. doi: 10.1097/SLA.0000000000001615

27. Mustonen KM, Vuola J. Acute renal failure in intensive care burn patients (ARF in burn patients). J Burn Care Res. (2008) 29:22737. doi: 10.1097/BCR.0b013e31815f3196

28. Pronina I, Malic C, Radulovic N, Bian J, Burnett MA, Jeschke MG. Acute kidney injury in burn victims: progression to dialysis. J Burn Care Res. (2015) 36:S66. doi: 10.1097/BCR.0000000000000251

29. Queiroz LF, Anami EH, Zampar EF, Tanita MT, Cardoso LT, Grion CM. Epidemiology and outcome analysis of burn patients admitted to an intensive care unit in a University Hospital. Burns. (2016) 42:65562. doi: 10.1016/j.burns.2015.08.002

30. Saffle JR, Sullivan JJ, Tuohig GM, Larson CM. Multiple organ failure in patients with thermal injury. Crit Care Med. (1993) 21:1673-83. doi: 10.1097/00003246-199311000-00016

31. Soltani A, Karsidag S, Garner W. A ten-year experience with hemodialysis in burn patients at los angeles county + USC medical center. J Burn Care Res. (2009) 30:832-5. doi: 10.1097/BCR.0b013e3181b480eb

32. Steinvall I, Bak Z, Sjoberg F. Acute kidney injury is common, parallels organ dysfunction or failure, and carries appreciable mortality in patients with major burns: a prospective exploratory cohort study. Crit Care. (2008) 12:R124. doi: $10.1186 /$ cc7032

33. Stewart IJ, Cotant CL, Tilley MA, Huzar TF, Aden JK, Snow $\mathrm{BD}$, et al. Association of rhabdomyolysis with renal outcomes and mortality in burn patients. J Burn Care Res. (2013) 34:318-25. doi: 10.1097/BCR.0b013e31825addbd

34. Tremblay R, Ethier J, Querin S, Beroniade V, Falardeau P, Leblanc M. Venovenous continuous renal replacement therapy for burned patients with acute renal failure. Burns. (2000) 26:638-43. doi: 10.1016/S0305-4179(00)00010-3

35. Witkowski W, Kawecki M, Surowiecka-Pastewka A, Klimm W, Szamotulska K, Niemczyk S. Early and late acute kidney injury in severely burned patients. Med Sci Monit. (2016) 22:3755-63. doi: 10.12659/MSM.895875

36. Yang HT, Yim H, Cho YS, Kym D, Hur J, Kim JH, et al. Assessment of biochemical markers in the early post-burn period for predicting acute kidney injury and mortality in patients with major burn injury: comparison of serum creatinine, serum cystatin-C, plasma and urine neutrophil gelatinaseassociated lipocalin. Crit Care. (2014) 18:R151. doi: 10.1186/cc13989

37. Yoon J, Kim Y, Yim H, Cho YS, Kym D, Hur J, et al. Analysis of prognostic factors for acute kidney injury with continuous renal replacement therapy in severely burned patients. Burns. (2017) 43:141826. doi: 10.1016/j.burns.2017.03.015

38. Yoon J, Kim Y, Kym D, Hur J, Yim H, Cho YS, et al. Subgroup analysis of continuous renal replacement therapy in severely burned patients. PLoS ONE. (2017) 12:e0189057. doi: 10.1371/journal.pone.0189057

39. Sabry A, Wafa I, El-Din AB, El-Hadidy AM, Hassan M. Early markers of renal injury in predicting outcome in thermal burn patients. Saudi J Kidney Dis Transpl. (2009) 20:632-8.

40. Chung KK, Coates EC, Smith DJ, Jr., Karlnoski RA, Hickerson WL, et al. Highvolume hemofiltration in adult burn patients with septic shock and acute kidney injury: a multicenter randomized controlled trial. Crit Care. (2017) 21:289. doi: 10.1186/s13054-017-1878-8

41. You B, Zhang YL, Luo GX, Dang YM, Jiang B, Huang GT, et al. Early application of continuous high-volume haemofiltration can reduce sepsis and improve the prognosis of patients with severe burns. Crit Care. (2018) 22:173. doi: 10.1186/s13054-018-2095-9 
42. Akers KS, Cota JM, Chung KK, Renz EM, Mende K, Murray CK. Serum vancomycin levels resulting from continuous or intermittent infusion in critically ill burn patients with or without continuous renal replacement therapy. J Burn Care Res. (2012) 33:e254-62. doi: 10.1097/BCR.0b013e31825042fa

43. Boucher BA, Hudson JQ, Hill DM, Swanson JM, Wood GC, Laizure SC, et al. Pharmacokinetics of imipenem/cilastatin burn intensive care unit patients undergoing high-dose continuous venovenous hemofiltration. Pharmacotherapy. (2016) 36:1229-37. doi: 10.1002/phar.1866

44. Chung KK, Juncos LA, Wolf SE, Mann EE, Renz EM, White CE, et al. Continuous renal replacement therapy improves survival in severely burned military casualties with acute kidney injury. J Trauma. (2008) 64(Suppl. 2):S179-85; discussion S85-7. doi: 10.1097/TA.0b013e3181608676

45. Hladik M, Tymonova J, Zaoral T, Kadlcik M, Adamkova M. Treatment by continuous renal replacement therapy in patients with burn injuries. Acta Chir Plast. (2001) 43:21-5.

46. Hong DY, Lee JH, Park SO, Baek KJ, Lee KR. Plasma neutrophil gelatinase-associated lipocalin as early biomarker for acute kidney injury in burn patients. J Burn Care Res. (2013) 34:e32632. doi: 10.1097/BCR.0b013e31827d1f36

47. Kym D, Cho YS, Yoon J, Yim H, Yang HT. Evaluation of diagnostic biomarkers for acute kidney injury in major burn patients. Ann Surg Treat Res. (2015) 88:281-8. doi: 10.4174/astr.2015.88.5.281

48. Planas M, Wachtel T, Frank H, Henderson LW. Characterization of acute renal failure in the burned patient. Arch Intern Med. (1982) 142:208791. doi: 10.1001/archinte.1982.00340250045009

49. Schneider DF, Dobrowolsky A, Shakir IA, Sinacore JM, Mosier MJ, Gamelli RL. Predicting acute kidney injury among burn patients in the 21st century: a classification and regression tree analysis. J Burn Care Res. (2012) 33:24251. doi: 10.1097/BCR.0b013e318239cc24

50. Sen S, Godwin ZR, Palmieri T, Greenhalgh D, Steele AN, Tran NK. Whole blood neutrophil gelatinase-associated lipocalin predicts acute kidney injury in burn patients. J Surg Res. (2015) 196:382-7. doi: 10.1016/j.jss.2015.03.033

51. Peng Y, Yuan Z, Li H. Removal of inflammatory cytokines and endotoxin by veno-venous continuous renal replacement therapy for burned patients with sepsis. Burns. (2005) 31:623-8. doi: 10.1016/j.burns.2005.02.004

52. Liu F, Huang ZG, Peng YZ, Wu J, He WF, Yuan ZQ, et al. [Clinical randomized controlled trial on the feasibility and validity of continuous blood purification during the early stage of severe burn]. Zhonghua Shao Shang Za Zhi. (2016) 32:133-9. doi: 10.3760/cma.j.issn.1009-2587.2016.03.002

53. Lopes JA, Jorge S, Neves FC, Costa AG, Prata MM, Caneira M, et al. Acute renal failure in severely burned patients. Resuscitation. (2007) 73:318. doi: 10.1016/j.resuscitation.2006.10.029

54. Demsey D, Mordhorst A, Griesdale DEG, Papp A. Improved outcomes of renal injury following burn trauma. Burns. (2019) 45:1024-30. doi: 10.1016/j.burns.2019.04.001

55. Mariano F, Tedeschi L, Morselli M, Stella M, Triolo G. Normal citratemia and metabolic tolerance of citrate anticoagulation for hemodiafiltration in severe septic shock burn patients. Intens Care Med. (2010) 36:173543. doi: 10.1007/s00134-010-1909-2

56. Bechir M, Puhan MA, Fasshauer M, Schuepbach RA, Stocker R, Neff TA. Early fluid resuscitation with hydroxyethyl starch 130/0.4 (6\%) in severe burn injury: a randomized, controlled, double-blind clinical trial. Crit Care. (2013) 17:R299. doi: 10.1186/cc13168

57. Bechir M, Puhan MA, Neff SB, Guggenheim M, Wedler V, Stover JF, et al. Early fluid resuscitation with hyperoncotic hydroxyethyl starch 200/0.5 $(10 \%)$ in severe burn injury. Crit Care. (2010) 14:R123. doi: 10.1186/c c9086

58. Chun W, Kim Y, Yoon J, Lee S, Yim H, Cho YS, et al. Assessment of plasma neutrophil gelatinase-associated lipocalin for early detection of acute kidney injury and prediction of mortality in severely burned patients. JBurn Care Res. (2018) 39:387-93. doi: 10.1097/BCR.0000000000000605

59. Clark AT, Li X, Kulangara R, Adams-Huet B, Huen SC, Madni TD, et al. Acute kidney injury after burn: a cohort study from the parkland burn intensive care unit. J Burn Care Res. (2019) 40:72-8. doi: 10.1093/jbcr/iry046

60. Depret F, Boutin L, Jarkovsky J, Chaussard M, Soussi S, Bataille A, et al. Prediction of major adverse kidney events in critically ill burn patients. Burns. (2018) 44:1887-94. doi: 10.1016/j.burns.2018.08.007
61. Hundeshagen G, Herndon DN, Capek KD, Branski LK, Voigt CD, Killion EA, et al. Co-administration of vancomycin and piperacillintazobactam is associated with increased renal dysfunction in adult and pediatric burn patients. Crit Care. (2017) 21:318. doi: 10.1186/s13054-0171899-3

62. Kumar AB, Andrews W, Shi Y, Shotwell MS, Dennis S, Wanderer J, et al. Fluid resuscitation mediates the association between inhalational burn injury and acute kidney injury in the major burn population. J Crit Care. (2017) 38:62-7. doi: 10.1016/j.jcrc.2016.10.008

63. Rakkolainen I, Vuola J. Plasma NGAL predicts early acute kidney injury no earlier than s-creatinine or cystatin $\mathrm{C}$ in severely burned patients. Burns. (2016) 42:322-8. doi: 10.1016/j.burns.2015.11.006

64. Ren H, Zhou X, Dai D, Liu X, Wang L, Zhou Y, et al. Assessment of urinary kidney injury molecule-1 and interleukin-18 in the early post-burn period to predict acute kidney injury for various degrees of burn injury. BMC Nephrol. (2015) 16:142. doi: 10.1186/s12882-015-0140-3

65. Sanchez-Sanchez M, Garcia-de-Lorenzo A, Cachafeiro L, Herrero E, Asensio MJ, Agrifoglio A, et al. Acute kidney injury in critically burned patients resuscitated with a protocol that includes low doses of Hydroxyethyl Starch. Ann Burns Fire Disasters. (2016) 29:183-8.

66. Rakkolainen I, Lindbohm JV, Vuola J. Factors associated with acute kidney injury in the Helsinki Burn Centre in 2006-2015. Scand J Trauma Resusc Emerg Med. (2018) 26:105. doi: 10.1186/s13049-018-0573-3

67. Tang CQ, Li JQ, Xu DY, Liu XB, Hou WJ, Lyu KY, et al. [Comparison of machine learning method and logistic regression model in prediction of acute kidney injury in severely burned patients]. Zhonghua Shao Shang Za Zhi. (2018) 34:343-8. doi: 10.3760/cma.j.issn.1009-2587.2018.06.006

68. Davies MP, Evans J, McGonigle RJ. The dialysis debate: acute renal failure in burns patients. Burns. (1994) 20:71-3. doi: 10.1016/0305-4179(94)90111-2

69. Helantera I, Koljonen V, Finne P, Tukiainen E, Gissler M. The risk for end-stage renal disease is increased after burn. Burns. (2016) 42:31621. doi: 10.1016/j.burns.2015.10.027

70. Thalji SZ, Kothari AN, Kuo PC, Mosier MJ. Acute kidney injury in burn patients: clinically significant over the initial hospitalization and 1 year after injury: an original retrospective cohort study. Ann Surg. (2017) 266:37682. doi: 10.1097/SLA.0000000000001979

71. Sterne JA, Egger M. Funnel plots for detecting bias in metaanalysis: guidelines on choice of axis. J Clin Epidemiol. (2001) 54:1046-55. doi: 10.1016/S0895-4356(01)00377-8

72. Zhang Z, Xu X, Ni H. Small studies may overestimate the effect sizes in critical care meta-analyses: a meta-epidemiological study. Crit Care. (2013) 17:R2. doi: 10.1186/cc11919

73. Clark WR, Ding X, Qiu H, Ni Z, Chang P, Fu P, et al. Renal replacement therapy practices for patients with acute kidney injury in China. PLoS ONE. (2017) 12:e0178509. doi: 10.1371/journal.pone.0178509

74. Zhou X, Dong P, Pan J, Wang H, Xu Z, Chen B. Renal replacement therapy modality in critically ill patients with acute kidney injury - a network meta-analysis of randomized controlled trials. J Crit Care. (2021) 64:8290. doi: 10.1016/j.jcrc.2021.03.011

75. Wang AY, Bellomo R. Renal replacement therapy in the ICU: intermittent hemodialysis, sustained low-efficiency dialysis or continuous renal replacement therapy? Curr Opin Crit Care. (2018) 24:437-42. doi: 10.1097/MCC.0000000000000541

76. Bellomo R, Ronco C, Kellum JA, Mehta RL, Palevsky P. Acute Dialysis Quality Initiative w. Acute renal failure - definition, outcome measures, animal models, fluid therapy and information technology needs: the second international consensus conference of the acute dialysis quality initiative (ADQI) group. Crit Care. (2004) 8:R204-12. doi: 10.1186/cc2872

77. Mehta RL, Kellum JA, Shah SV, Molitoris BA, Ronco C, Warnock DG, et al. Acute kidney injury network: report of an initiative to improve outcomes in acute kidney injury. Crit Care. (2007) 11:R31. doi: 10.1186/c c5713

78. Khwaja A. KDIGO clinical practice guidelines for acute kidney injury. Nephron Clin Pract. (2012) 120:c179-84. doi: 10.1159/000339789

79. Rodrigues FB, Bruetto RG, Torres US, Otaviano AP, Zanetta DM, Burdmann EA. Incidence and mortality of acute kidney injury after myocardial infarction: a comparison between KDIGO and RIFLE criteria. PLoS ONE. (2013) 8:e69998. doi: 10.1371/journal.pone.0069998 
80. Ulger F, Pehlivanlar Kucuk M, Kucuk AO, Ilkaya NK, Murat N, Bilgic B, et al. Evaluation of acute kidney injury (AKI) with RIFLE, AKIN, CK, and KDIGO in critically ill trauma patients. Eur J Trauma Emerg Surg. (2018) 44:597-605. doi: 10.1007/s00068-017-0820-8

81. Mosier MJ, Pham TN, Klein MB, Gibran NS, Arnoldo BD, Gamelli RL, et al. Early acute kidney injury predicts progressive renal dysfunction and higher mortality in severely burned adults. J Burn Care Res. (2010) 31:8392. doi: 10.1097/BCR.0b013e3181cb8c87

82. Clark A, Neyra JA, Madni T, Imran J, Phelan H, Arnoldo B, et al. Acute kidney injury after burn. Burns. (2017) 43:898-908. doi: 10.1016/j.burns.2017.01.023

Conflict of Interest: The authors declare that the research was conducted in the absence of any commercial or financial relationships that could be construed as a potential conflict of interest.
Publisher's Note: All claims expressed in this article are solely those of the authors and do not necessarily represent those of their affiliated organizations, or those of the publisher, the editors and the reviewers. Any product that may be evaluated in this article, or claim that may be made by its manufacturer, is not guaranteed or endorsed by the publisher.

Copyright $\odot 2021$ Duan, Cai, Li, Chen and Chen. This is an open-access article distributed under the terms of the Creative Commons Attribution License (CC BY). The use, distribution or reproduction in other forums is permitted, provided the original author(s) and the copyright owner(s) are credited and that the original publication in this journal is cited, in accordance with accepted academic practice. No use, distribution or reproduction is permitted which does not comply with these terms. 